\title{
Older people, information-giving and active agency practices in health, social care and housing: theory, evidence and reflections
}

\author{
Andrew J. E. Harding (10) \\ Division of Health Research, Faculty of Health and Medicine, Lancaster University, Lancaster, UK \\ Email: a.harding5@lancaster.ac.uk
}

(Accepted 22 November 2021)

\begin{abstract}
That older people should be consumers and active agents has dominated policy discourse across health, social care and housing that has a core care function. This discourse has some established and long-standing critics, such as Gilleard and Higgs, and yet the central question(s) a consumerist discourse raises remains surprisingly relevant today. The purpose of this forum article is to reconsider the viability of active agency amongst older people in the context of empirical research on information-giving across health, social care and housing that has been published since the paper by Gilleard and Higgs in 1998. Information-giving is the key consumer choice mechanism, and yet research is currently located in separate literatures. Giving these separate fields some coherence engages with and provides important empirical commentary. There is little or no evidence that information alone triggers active agency for older people in regard to their health, social care or housing. However, there is consistent evidence that discussion, deliberation and dialogue or the practices associated with Habermas' theory of communicative action - are desirable to older people in the context of active agency. More research is needed to demonstrate efficacy beyond communicative approaches being desirable.
\end{abstract}

Keywords: consumer; citizen; Habermas; communicative action; welfare

\section{Introduction}

The rule that governs transactions, supply and demand in markets is a principle that was described by Adam Smith. He referred to consumers flexing their 'invisible hand' as indirectly dictating the goods and services that are provided (Smith, [1776] 2000). If consumers' decisions are responsible for directly shaping the goods and services that are on offer in the marketplace, it becomes important to be informed about them. One popular perspective, present in much health and social care policy discourse, is that people require accessible and high-quality information in order to become informed and active agents (Department of Health, 
2010). Over the last few decades, this principle has increasingly been applied to people who access and engage with health, social care and wider welfare provision such as housing that has a core care function (Gilleard and Higgs, 1998; Moffatt et al., 2012; Armstrong, 2014; Harding et al., 2018b, 2020; Baxter et al., 2020).

Individuals use state funds to interact with the markets in order to procure goods and services to meet their own social care needs. These are known as 'cash for care' and individual budget schemes (Glendinning, 2008; Moran et al., 2013). Furthermore, the increasingly exclusionary eligibility criteria to access statutory funding has increased the number of people who use their own funds to purchase social care in the marketplace (Henwood, 2011). Housing may well have a more established relationship with the need to make choices throughout the lifecourse (Mills, 2009). Yet maintaining independence or potentially requiring greater support will often mean having to reassess the home environment and consider types of retirement housing and or care/nursing homes. Social care and housing have a mixed economy of information provision and other support provided by local government and third-sector organisations (Harding et al., 2018b, 2020). However, the direction of government policy and the behavioural assumptions that such policies make is best illustrated by highlighting reforms to the United Kingdom (UK) National Health Service (NHS).

In the UK, the NHS and Community Care Act 1990 is often referred to as a pivotal moment in discussions about care markets and the conceptualisation of welfare services as a commodity or consumer good. The legislation led to the introduction of market mechanisms in the form of the purchaser/provider split and the internal market. This introduced a transactional element within the NHS, and is widely cited as the beginning of the rationale to introduce market mechanisms: to introduce more efficient and responsive services through competition and offer choice to allow users to flex their invisible hand. Since the inception of the internal market in 1990, various reforms have opened up the possibility of NHS services being delivered by private and third-sector organisations.

Chief academic and policy architect Julian Le Grand (2007) proposed choicebased reforms as an alternative to what were framed as inequitable bureaucratic allocation mechanisms (Greener and Powell, 2009a). Improvements in the quality of care were to be driven by introducing the concept of consumer choice through patients using their invisible hand and dissatisfied users going elsewhere, thereby incentivising providers to improve provision. However, as Greener and Powell (2009a) point out, Le Grand has not always been supportive of positioning choice as a key means of accessing and engaging with provision. After the conception of the internal market in 1990, Le Grand stated that on account of considerable information asymmetry, 'neither before nor after the treatment can consumers easily acquire information that will enable them to make an informed choice' (Le Grand et al., 1992: 45). In other words, 'patients are extremely flawed consumers' (Greener and Powell, 2009a: 561-562).

And yet, despite such concerns, the direction and intention of UK government policy has been clear. Choice of provider was championed and gradually extended by the Department of Health for the decade after 2000 (Department of Health, 2000, 2004, 2006a, 2006b, 2007). However, the Coalition government (20102015) chose to accelerate and extend these policies further. In the now infamous 
White Paper Equity \& Excellence: Liberating the NHS (Department of Health, 2010), choice was to extend to treatment choices: 'Patients will have choice of any provider, choice of consultant-led team, choice of GP practice and choice of treatment' (Department of Health, 2010: 3). This sought to directly move responsibility away from professionals to those needing treatment. Indeed, the 2010 White Paper explicitly said: 'In return for greater choice and control, patients should accept responsibility for the choices they make' (Department of Health, 2010: 16).

Given older people have the largest interaction with health and welfare services, any reform or position on how health and welfare provision is accessed and engaged with disproportionately impacts on older people. There are many vocal critics of positioning older people as consumers in the context of health and care. In what has become a seminal paper, Gilleard and Higgs (1998) offer a critical perspective that dismisses the role and application of choice and consumer culture to health-care provision for retired people. They provide what have become longstanding questions and issues on the matter of active agency: who does it benefit, what is desirable and what can be considered to be 'active' in the context of older people, agency and care? More fundamentally, does choice and consumer culture falsely frame agency and action as a private concern where individualism is regarded as emancipatory? Although Gilleard and Higgs voiced their concerns over 20 years ago, these questions remain surprisingly relevant today.

The application of consumer culture that the aforementioned authors were suspicious about has a far more prominent place in the current structure of health, social care and other related areas such as housing that have a core care function. The purpose of this forum article is to present evidence from empirical work published since Gilleard and Higgs' (1998) paper to answer the following question: can older people be considered active agents in regard to heath, social care and housing, and if so how? One way to do this is to synthesise the theoretical and empirical field of information-giving. For two reasons it is important that some coherence is afforded to this field. Firstly, information is positioned as the key underlying mechanism that triggers choice and active agency. However, and secondly, the empirical research field of information-giving is currently disparate and situated across a number of distinct literatures which are largely unknown to one another. In order to address this weakness in the evidence base, firstly an overview of key theoretical propositions concerning two different theories of agency are presented. Secondly, empirical research is then presented on the role of information-giving across key areas of health, social care and housing that concern older people.

\section{Consumer versus citizen theories of agency: useful when highlighting a theoretical distinction}

\section{Information as a consumerist tool}

The citizen and the consumer have different perspectives on human nature and make different behavioural assumptions about agency. As Clarke et al. (2007: 2) state: 'The citizen is embodied in public identifications and practices ... By contrast, the consumer is a figure motivated by personal desires, pursuing their own interests through anonymous transactions.' The distinction between the citizen and the 
consumer is useful to highlight key theoretical distinctions on how support is offered and structured to those who access and engage with health, social care and housing-related services.

The anonymous transactions and personal desires associated with the consumer (Clarke et al., 2007) have traditionally been regarded as being consistent with services being reactive and relying on the instrumental rationality of consumers in making contact (Stiglitz, 2008). Not only does a consumerist approach presume a level of agency in order to initiate contact and access, but there are also implications for the giving of information in terms of whose interests are privileged whose benefit does information-giving serve? In a consumerist approach, the anonymous transactional manner of information-giving will mean that meaningful engagement largely ends with the imparting of information. Information is sought, and generic information is provided - full stop. There is minimal possibility of imparting more bespoke information or support because the transaction is a consumerist one where responsibility for action lies firmly with the individual. Another major and linked issue is that the content, or what is constituted as information, is likely predetermined. In the context of this forum article, examples might include predetermined characteristics about the service, client satisfaction measures or performance indication measures, or even car parking or transport links (Greener, 2007; Greener and Powell, 2009b). These may likely be selectively chosen, superficial or not responsive to what people want or need when requiring to make informed decisions about care. This consumerist approach to information-giving arguably serves the provider more so than the recipient. It will likely have meant a short engagement with generic information and require minimal resource input.

\section{Information as a consumerist tool in the 'big data' era and the digital divide}

In recent years, the context of new media, 'big data' and targeted informationgiving has become a controversial issue. This refers to the relatively new phenomena of commercial organisations using people's digital footprint and other pieces of personal data to target them with marketing information, including health-related goods and services. In the context of health care, the rationale for doing this is supposedly well meaning - to enable people to take control of their lives. Yet, others have pointed out that information-giving when directed straight to consumers in this context can also lead to what has been referred to as 'disease-mongering'. This is where commercial information-giving is exploitative and manipulates diagnostic criteria in order to increase unnecessary consumption (Mintzes, 2006). In what Deborah Lupton (2015) refers to as a 'corporatized context' is the contention that motives around health promotion in the digital era are blurred with individualised aspects of consumer marketing and presenting corporate goods and services as a means of alleviating health and social inequalities. In contrast, it is an established view in the academic community that the underlying cause(s) and remedy of health and social inequalities require both broader and more structurally informed solutions (Lupton, 2015).

The digital era also presents further issues for older people in the context of information-giving. Information provision is increasingly and sometimes exclusively held online. Quan Hasse et al. (2018) find there is a great deal of variation 
in skills and attitudes to older people's online activities. However, a consistent research finding is that older people are less likely and able to access and use the internet effectively (Lan Fang et al., 2019) and this is further exacerbated by age (i.e. the 'oldest old'), poor health, socio-economic disadvantage and social isolation (Hargittai et al., 2019; Matthews et al., 2019; Stockwell et al., 2021). If the least healthy and oldest older people tend to be the least well equipped to access and use information resources (Gilleard and Higgs, 2017), it would seem the 'digital divide' is doubly disadvantageous for those who need access to information and services the most. Given the key role of technology and the internet in modern information provision, the critique of a consumerist approach that Gilleard and Higgs (1998) presented in the pre-digital era is now arguably far more concerning for older people - and particularly acute for the oldest in society. The digital era continues the trend of shifting responsibility for health and care services - what they offer, how they are accessed and engaged with - from the state to the individual or family (Gilleard and Higgs, 1998). However, the emergence of informationgiving in the digital and 'big data' era not only offers information providers and commercial organisations a more substantive platform, but does so in a way that better serves their own interests than it does older recipients of information.

Consumerist approaches to information-giving are counter-intuitive to those who propose that active agency is contingent on building rapport, nurturing relationships, trust and discussion. There is a great deal of theory which suggests that information-giving that follows a citizenship approach is likely to be better for recipients and possibly more efficacious.

\section{Citizenship: agency through discussion, dialogue, relationship building and trust}

The notion of the 'citizen' can be traced back to ancient Athens, where matters of the day were discussed and deliberated over in public forums (Powell et al., 2009). In contrast to the isolated consumer where information-giving and agency is framed as an individual concern, the citizen draws on the relational elements of discussion, deliberation and exchanging of views. As Silverstein (2016: 517) states: 'Human beings are agents. We can deliberate about what to do-reflecting on our desires and our circumstances - and then act on the basis of that deliberation.'

Empowering the citizen is contingent upon the relationships that are established during discussion, deliberation and an exchange of views. The primary reason to support furthering discussion, deliberation and exchanging views is the proposition by Herbert Simon $(1955,1956)$ in his theory of bounded rationality. Simon proposed that agency is dependent on, and conditioned by, the individual and the wider structural context within which a decision takes place (Collet, 2009). Such issues are complex. Simon's 'bounded rationality', and other theories of agency based on it (e.g. Bourdieu's theory of 'habitus' ([1990] 1999) and Giddens' (1984) 'structuration' theory), are overarching frameworks about individual behaviour. However, they do not conceptualise the means by which active agency is enabled. Jurgen Habermas' $(1992 a, 1992 b)$ theory of 'communicative action' fills this gap and proposes how and why acts of deliberation and discussion can be conceptualised as a means of enabling understanding, empowerment and agency. 
Habermas (1992a, 1992b) acknowledges the complexity in the interaction between the social world, individual and structural contexts. On this basis, he proposes that agents will have a set of different, varying and incommensurable standards of choice. An agent must be able to understand their place within wider socio-political structures if they are to settle on a preferable course of action. The meaning and consequences of alternatives must be fully understood in order to come to an instrumental action and make a decision. It is this meaning behind an instrumental act that Habermas $(1992 a, 1992 b)$ refers to as a 'noninstrumental action type' (Heath, 2001: 17).

While in isolation information is a consumerist tool, it is grounded in words, sentences and language. Words and sentences are critical to shaping the noninstrumental meaning that lies behind instrumental action. Linguistic structures and speech are the crux of human action, how humans rationalise action and are therefore intrinsic to validity claims (Honneth and Joas, 1991). In other words, Habermas $(1992 a, 1992 b)$ regards agency to be based on conveying meaning from information, emotional expression, establishing social relationships, and utilising dialogue to discuss and exchange views (Heath, 2001).

The rationale of Habermas' communicative action underpins how agency, action and empowerment are understood in related fields such as higher education and global citizenship (Bosio, 2021). Paulo Freire, a critical pedagogical theorist, used the term 'conscientization' as a means of highlighting why a critical understanding of one's position in social reality through reflection is a critical precursor for action (Freire, 1970). Originally based on critically exploring adult literacy programmes and processes, Freire's ideas have become a central pillar of critical pedagogy theory in higher education and global citizenship - particularly in light of what many regard as the hegemony of neo-liberal approaches to learning which directly undermine critical thought through reflection and dialogue (Giroux, 2014). In light of these theoretical positions, what can be learnt from existing empirical literature in respect of what triggers active agency for older people in the context of health, social care and housing that has a core care function?

\section{Health and social care}

Greener and Mannion (2009) undertook an ethnographic study on the implementation of choice policies when they were first introduced in an English NHS Trust. One key finding concerning the role of information on providers was that choices and referral patterns remained largely unchanged despite the greater availability of performance-related data (Greener and Mannion, 2009). There is some evidence that less-formal information sources have a role in older people's choices of provider - such as stories in local newspapers/media, the accessibility of car parking and feedback from family members (Harding et al., 2014). There is evidence that older people view information-giving as part of a person-centred and respectful caring relationship when making or being involved in care and treatment decisions. Yet, this does not necessarily mean older people wish to be active agents in decision-making about treatment or care (Bastiaens et al., 2007).

While age may increase the need to access health services, it is also associated with diminished information-seeking skills. The least healthy older people tend 
to be the least well equipped to use information resources (Gilleard and Higgs, 2017), particularly in the context of cognitive decline (Meinow et al., 2011). In addition, others have found that age is associated with a decreased desire to engage with information (Duggan and Bates, 2008). In contrast, there is evidence that older people desire higher-quality information during the dementia journey, though in the context of a paucity of information and wider services to support people living with dementia (Behrman et al., 2017; Kupeli et al., 2019).

Given information asymmetries, patients may well be flawed consumers, but existing evidence suggests that older people may also tend to be unwilling consumers. If active agency in older people tends not to be based on the provision of information, is it triggered by communicative action instead? Interestingly, there is little evidence to support that communicative action triggers active agency either - though there is evidence that engaging in discussion is desirable as part of a respectful and person-centred clinician-patient relationship. Perhaps it is worth reconsidering what or how active agency is conceptualised, and to redraw the boundary to somewhere closer to shared decision-making.

What about the role of information and active agency in social care? In the UK, a fairly substantial market exists in social care on account of the personalisation agenda - which is care provided in the community (often in the home, or care/ nursing homes) outside formal health settings such as hospitals. If viable choices are on offer, what evidence is there for active agency and what is this triggered by? A common source of support for social care self-funders (those not in receipt of state support) has been found to be personal experiences, family and friends (Baxter et al., 2020). As such, experiential and subjective experiences tend to be trusted sources of information (Turnpenny and Beadle-Brown, 2014). However, making services contingent on accessing information is likely to extend inequalities because it requires high levels of skill, energy and resources in order to gather it (Stevens et al., 2011), let alone considering what information is available. In a care home context, Moore (2020) expresses a concern that information tends to be imperfect and of limited relevance, which may allow providers to engage in opportunistic money-making behaviours that are not always consistent with quality care.

Consistent recommendations on older people's information needs concerning social care mitigates some of these issues and points to the need for information resources to be located in a central place, that information needs to be imparted early and that support is provided to discuss options (Baxter et al., 2008, 2020; Baxter and Glendinning, 2011). In terms of content, Rodrigues (2020) highlights that care is an experience and older people value information on the quality of caring relationships - something in relation to information-giving that lends itself to relational and deliberative citizenship-based approaches. In other words, accessing, considering and acting on information cannot be regarded as an independent consumer-driven activity, but based on relational engagements with others, involving discussion and deliberation. An example that has shown promise are services located in General Practice surgeries that provide 'in-depth advice' about benefits and debt. A study of such a service located in General Practice highlights impact on mental health and financial strain outcomes, although a minority of the sample were over 65 years of age (Woodhead et al., 2017). Evidence elsewhere suggests a 
similar Citizens' Advice Bureau service provides significant social and financial return on investment (Cressey et al., 2014). Advance care plans are written statements that set out preferences for care and provide another example for exploring information-giving concerning older people in the context of care. It is recommended practice for the development of an advance care plan to involve the provision of information to patients (or residents in care/nursing homes) and family carers. After looking at relevant information, a discussion is facilitated and care plans are based on a dialogue between patients or residents (if possible), family carers and health and/or social care professionals (Brazil et al., 2017; Rietjens et al., 2017). There is some indication of beneficial outcomes relating to advance care planning (Weathers et al., 2016), although some beneficial outcomes can be less clear (Brazil et al., 2017; Jimenez et al., 2018). However, initiating advance care plan conversations can be difficult and complex. While it is good practice for plans about care to be ongoing, it is common for formal and documented care plans to be initiated close to death - if at all (Brazil et al., 2017; Rietjens et al., 2017). In addition, there are cultural issues to consider that relate to autonomy in a health and decision-making context. It may not always be culturally appropriate or regarded as a normative social practice to provide information and initiate conversations about care, or there may be cultural norms as to who is involved in these discussions. For example, physician authority and mostly maledriven family values dictate decision-making concerning advance care plans for patients in an East Asian context on account of how Confucianism privileges 'filial piety' (Cheng et al., 2020). This context seems to place a boundary around and limit involvement in participative and communicative acts. It is a good example of a cultural dimension which gets scant attention in the literature.

\section{Housing}

In some ways it is difficult to distinguish housing from social care. Many of the decisions and choices concerning housing may well have a social care and even health-care remit. However, some make a distinction between health, social care and housing because decisions and active agency concerning housing are likely to be more familiar on account of a deeper, historical and cultural association with making choices (Mills, 2009). However, housing choices can be very challenging, emotive, personal and involve complex 'push' and 'pull' factors for older people - particularly if a person is finding it difficult to remain independent in their own home (Croucher et al., 2007; Harding et al., 2020). Common alternatives to mainstream dwellings for older people in the UK are sheltered/extra-care housing, assisted living or other types of retirement developments. The collective term 'specialist housing' is used when referring to this type of housing (Harding et al., 2018a). However, in the UK there is a chronic shortage of supply and for individuals there are often surprisingly few viable options (Harding et al., 2018a, 2020; Robinson and Wilson, in press).

The provision of generic information to older people considering moving into specialist housing is best summarised by one participant in a realist evaluation study who stated 'it can't be answered in an information pack ... it's a difficult problem which you can't really answer in this report'. The issue was 'difficult' 
(Harding et al., 2020) and not adequately addressed by the provision of generic information. For this reason, participants in many different circumstances greatly valued and independently pursued discussion, deliberation and dialogue about their housing issue. Older people did not regard information-seeking as a one-off anonymous transaction. Instead, they thought empowerment and action should be based on relational engagements with others and after substantial discussion and deliberation - or the practices that are central to Habermas' theory of communicative action. This type of support in the form of intensive face-to-face advice and advocacy with other related services has demonstrable impact for older people considered vulnerable (Burgess and Morrison, 2016). However, Harding et al. (2020) highlight how more intensive support would also clearly benefit those with limited economic resources who may not have been considered vulnerable.

\section{Contrasting theory and evidence}

In theory, and often in practice, information tends to be defined as generic material, and not bespoke or individualised in any way. This definition and its application are very significant because there is little or no evidence that information alone triggers active agency for older people in regard to their health, social care or housing. Information-giving in these areas is not regarded by older people as an independent, anonymous or economic activity. There is consistent evidence that discussion, deliberation and dialogue - or the practices associated with Habermas' theory of communicative action - are desirable to older people when seeking to become informed. Active agency for older people should be a supported process. This may involve engaging with generic information, but should almost always involve discussion, deliberation and dialogue in order to process information as a means for older people to make or shape decisions about care. At the very least, current evidence moves the consumer versus citizen theoretical divide from being a distinction to a continuum. However, it is important to acknowledge the role of context, and that more research is needed to understand these issues better.

\section{Areas for further research, consideration and reflection}

There is surprisingly limited evidence that communicative practices have beneficial outcomes beyond being a desirable process. This is particularly interesting given its desirability in theoretical and empirical literature. The advance care planning literature highlights interesting issues around how communicative approaches are likely to have a cultural and wider contextual dimension. It needs to be acknowledged that communicative approaches will likely also highlight inequalities. Where access to information has been shown to be contingent on social networks, skill, energy and resources, there is little evidence to suggest that communicative approaches will not also privilege the more able, skilled and resourced. However, this could be mitigated by implementing more substantive communicative approaches. One example is the substantial involvement reflected in advocacy provision, although the act of advocating on behalf of someone seems to go beyond the boundaries of what might be considered a communicative act between an older person and their advocate. Yet, in-depth advice and advocacy around benefits, debt, housing and other welfare issues have fairly consistent beneficial outcomes. 
There is a clear need for more communicative forms of support to be implemented in practice across a broad spectrum of health, social care, housing and other related areas, and for this to be evaluated. This is particularly urgent in instances where cognitive abilities and health decrease (Meinow et al., 2011; Gilleard and Higgs, 2017), such as information-giving and support at the point of and after a dementia diagnosis (Behrman et al., 2017; Kupeli et al., 2019). Further research would benefit from developing theory in order to advance what is a fairly underdeveloped field. Realist methodology is an approach where theory development is key, and is a research approach recommended for further use in this field (Harding et al., 2018b). The central aim of realist methodology in reviews of literature and empirical evaluation is to develop and refine theory in respect of how and why programmes work (or do not work), for whom and in what circumstances (Emmel et al., 2018). Unpicking this level of detail and nuance is particularly relevant given concerns that even communicative approaches may favour the more able, highlight inequalities, and may have a cultural and wider contextual dimension. Comparative evaluations between consumerist and communicative approaches to information-giving are also welcome in order to highlight differences.

The increasing movement to online information provision is concerning given the digital divide further exacerbates the issues initially raised by Gilleard and Higgs (1998) in respect of consumerism and discussed here in the context of information-giving. Research consistently finds that the least healthy, resourced and old older people (i.e. those who require access to support, information and services the most) are disadvantaged by the digital divide. In this context, another consideration is the longer-term effect of how the COVID-19 pandemic will impact on formal health and welfare service configuration. Many services have transitioned to operating either partially or fully remotely. On this basis, finding ways of fully engaging older people in the context of information-giving involving technology, and in a manner that is communicative and impactful, is particularly pressing. This forum article is largely reflective of Gilleard and Higgs' (1998) position from over two decades ago. A reflection with which to end this forum article is to consider the reasons why information-based services have such a central role in access and engaging with health and care provision. Underlying issues with the service that provided generic information to older people considering specialist housing is a real-world example of the theoretical positions discussed in this forum article. In this case study, the provision of mostly predetermined information seemed to be prioritised over more communicative approaches because it was financially cheaper and produced a greater quantity of quicker engagements better aligned to government funding targets (Harding et al., 2020). In this case, there was a clear dichotomy between efficiency, in the context of economics, and effectiveness for the recipients of support (or at least what was perceived to be desirable or better). Generic and predetermined information will invariably be financially cheaper as it does not require significant human input after it is developed. Unlike communicative approaches, there is less or no ongoing activity or cost. Cheap and quick may be desirable for funders and service providers, where notions of quantity may blur the pursuit of quality. This is a highly unsatisfactory state of affairs. There are significant and underlying assumptions about the role of information 
in respect of active agency that require challenging at political, commissioning and service design levels.

Conflict of interest. The author declares no conflicts of interest.

\section{References}

Armstrong D (2014) Actors, patients and agency: a recent history. Sociology of Health \& Illness 36, 163-174.

Bastiaens H, Van Royen P, Pavlic DR, Raposo V and Baker R (2007) Older people's preferences for involvement in their own care: a qualitative study in primary health care in 11 European countries. Patient Education \& Counselling 68, 33-42.

Baxter K and Glendinning C (2011) Making choices about support services: disabled adults' and older people's use of information. Health \& Social Care in the Community 19, 272-279.

Baxter K, Glendinning C and Clarke S (2008) Making informed choices in social care: the importance of accessible information. Health \& Social Care in the Community 16, 197-207.

Baxter K, Heavey E and Birks Y (2020) Choice and control in social care: experiences of older self-funders in England. Social Policy \& Administration 53, 460-474.

Behrman S, Wilkinson P, Lloyd HM and Vincent C (2017) Patient safety in community dementia services: what can we learn from the experiences of caregivers and healthcare professionals? Age and Ageing 46, 518-521.

Bosio E (ed.) (2021) Conversations on Global Citizenship Education: Perspectives on Research, Teaching, and Learning in Higher Education. London: Routledge.

Bourdieu P ([1990] 1999) The Logic of Practice. Stanford, CA: Stanford University Press.

Brazil K, Carter G, Cardwell C, Clarke M, Hudson P, Froggatt K, McLaughlin D, Passmore A and Kernohan G (2017) Effectiveness of advance care planning with family carers in dementia nursing homes: a paired cluster randomized controlled trial. Palliative Medicine 32, 603-612.

Burgess G and Morrison N (2016) Improving housing outcomes: the value of advice and support for vulnerable older people. Journal of Housing and the Built Environment 31, 197-211.

Cheng SY, Lin CP, Chan HY, Martina D, Mori M, Kim SH and Raymond NG (2020) Advance care planning in Asian culture. Japanese Journal of Clinical Oncology 50, 976-989.

Clarke J, Newman J, Smith N, Vidler E and Westmarland L (2007) Creating Citizen-consumers: Changing Publics and Changing Public Services. London: Sage.

Collet F (2009) Does habitus matter? A comparative review of Bourdieu's habitus and Simon's bounded rationality with some implications for economic sociology. Sociological Theory 27, 419-434.

Cressey P, Milner S, Farr M, Abercrombie N and Jaynes B (2014) IPR Policy Brief-Proving the Value of Advice: A Study of the Impact of Citizens' Advice Bureau Services. Bath, UK: University of Bath.

Croucher K, Hicks L, Bevan M and Sanderson D (2007) Comparative Evaluation of Models of Housing with Care for Later Life. York, UK: Joseph Rowntree Foundation.

Department of Health (2000) The NHS Plan: A Plan for Investment, a Plan for Reform. London: Department of Health.

Department of Health (2004) Choosing Health: Making Healthier Choices Easier. London: Department of Health.

Department of Health (2006a) Our Health, Our Care, Our Say: A New Direction for Community Services. London: Department of Health.

Department of Health (2006b) Patient Choice. London: Department of Health.

Department of Health (2007) The NHS in England: Operating Framework for 2008-9. London: Department of Health.

Department of Health (2010) Equity \& Excellence: Liberating the NHS. London: Her Majesty's Stationery Office.

Duggan C and Bates I (2008) Medicine information needs of patients: the relationships between information needs, diagnosis and disease. Quality and Safety in Health Care 17, 85-89.

Emmel N, Greenhalgh J, Manzano A, Monaghan M and Dalkin S (eds) (2018) Doing Realist Research. London: Sage. 
Freire P (1970) Cultural action and conscientization. Harvard Educational Review 40, 452-477.

Giddens A (1984) The Constitution of Society. Cambridge: Polity Press.

Gilleard C and Higgs P (1998) Old people as users and consumers of healthcare: a third age rhetoric for a fourth age reality? Ageing \& Society 18, 233-248.

Gilleard C and Higgs P (2017) Ageing, corporeality and social divisions in later life. Ageing \& Society 37, 1681-1702.

Giroux HA (2014) Neoliberalism's War on Higher Education. Chicago, IL: Haymarket Books.

Glendinning C (2008) Increasing choice and control for older and disabled people: a critical review of new developments in England. Social Policy and Administration 42, 451-469.

Greener I (2007) Are the assumptions underlying patients choice realistic?: a review of the evidence. British Medical Bulletin 83, 249-258.

Greener I and Mannion R (2009) Patient choice in the NHS: what is the effect of choice policies on patients and relationships in health economies? Public Money \& Management 29, 95-100.

Greener I and Powell M (2009a) The other Le Grand? Evaluating the 'Other Invisible Hand' in welfare services in England. Social Policy \& Administration 43, 557-570.

Greener I and Powell M (2009b) The evolution of choice policies in UK housing, education and health policy. Journal of Social Policy 38, 63-81.

Habermas J (1992a) Theory of Communicative Action, Vol. 1, Reason and the Rationalisation of Society. Boston, MA: Beacon.

Habermas J (1992b) The Theory of Communicative Action, Vol. 2, Lifeworld and System: A Critique of Functional Reason. Boston, MA: Beacon.

Harding AJE, Sanders F, Medina Lara A, Van Teijlingen ER, Wood C, Galpin D, Baron S, Crowe S and Sharma $\mathbf{S}$ (2014) Patient choice for older people in English NHS primary care: theory and practice. ISRN Family Medicine 2014, 742676.

Harding AJE, Parker J, Hean S and Hemingway A (2018a) Supply-side review of the UK specialist housing market and why it is failing older people. Housing, Care and Support 21, 41-50.

Harding AJE, Parker J, Hean S and Hemingway A (2018b) Efficacy of telephone information and advice on welfare: the need for realist evaluation. Social Policy \& Society 17, 1-21.

Harding AJE, Hean S, Parker J and Hemingway A (2020) 'It can't really be answered in an information pack...': a realist evaluation of a telephone housing options service for older people. Social Policy and Society 19, 361-378.

Hargittai E, Piper AM and Morris MR (2019) From internet access to internet skills: digital inequality among older adults. Universal Access in the Information Society 18, 881-890.

Heath J (2001) Communicative Action and Rational Choice. Cambridge, MA: MIT Press.

Henwood M (2011) Journey Without Maps: The Decisions and Destinations of People Who Self Fund. London: Putting People First Consortium.

Honneth A and Joas H (1991) Introduction. In Honneth A and Joas H (eds). Communicative Action: Essays on Jurgen Habermas's Theory of Communicative Action. Cambridge, MA: MIT Press, pp. 1-6.

Jimenez G, Tan WS, Virk AK, Low CK, Car J and Yan Ho AH (2018) Overview of systematic reviews of advance care planning: summary of evidence and global lessons. Journal of Pain and Symptom Management 56, 436-459.

Kupeli N, Sampson EL, Leavey G, Harrington J, Davis S, Candy B, King M, Nazareth I, Jones L and Moore K (2019) Context, mechanisms and outcomes in end-of-life care for people with advanced dementia: family carers perspective. BMC Palliative Care 18, 87.

Lan Fang M, Canham S, Battersby L, Sixsmith J, Wada M and Sixsmith A (2019) Exploring privilege in the digital divide: implications for theory, policy and practice. The Gerontologist 59, 1-15.

Le Grand J (2007) The Other Invisible Hand: Delivering Public Services Through Choice and Competition. Princeton, NJ: Princeton University Press

Le Grand J, Propper C and Robinson R (1992) The Economics of Social Problems, 3rd Edn. London: Palgrave Macmillan.

Lupton D (2015) Health promotion in the digital era: a critical commentary. Health Promotion International 30, 174-183.

Matthews K, Nazroo J and Marshall A (2019) Digital inclusion in later life: cohort changes in internet use over a ten-year period in England. Ageing \& Society 39, 1914-1932. 
Meinow B, Parker MG and Thorslund M (2011) Consumers of eldercare in Sweden: the semblance of choice. Social Science \& Medicine 73, 1285-1289.

Mills N (2009) The consumer and social housing. In Simmons R, Powell M and Greener I (eds). The Consumer in Public Services: Choice, Values and Difference. Bristol, UK: Policy Press, pp. 137-155.

Mintzes B (2006) Disease mongering in drug promotion: do governments have a regulatory role? PLOS Medicine 3, e198.

Moffatt S, Higgs P, Rummery K and Jones IR (2012) Choice, consumerism and devolution: growing old in the welfare state(s) of Scotland, Wales and England. Ageing \& Society 32, 725-746.

Moore S (2020) Of myths and markets: how marketisation of the care home sector contributes to circumstances where abuse is more likely to occur and continue. Journal of Adult Protection 22, 315-331.

Moran N, Glendinning C, Wilberforce M, Stevens M, Netten A, Jones K, Manthorpe J, Knapp M, Fernandez JL, Challis D and Jacobs S (2013) Older people's experiences of cash-for-care schemes: evidence from the English Individual Budget pilot projects. Ageing \& Society 33, 826-851.

Powell M, Doheny S, Greener I and Mills N (2009) Introduction: managing the 'unmanageable consumer'. In Simmons R, Powell M and Greener I (eds). The Consumer in Public Services: Choice, Values and Difference. Bristol, UK: Policy Press, pp. 1-17.

Quan-Haase A, Williams C, Kicevski M, Elueze I and Wellman B (2018) Dividing the grey divide: deconstructing myths about older adults' online activities, skills, and attitudes. American Behavioral Scientist 62, 1207-1228. doi:10.1177/0002764218777572.

Rietjens JAC, Sudore RL, Connolly M, van Delden JJ, Drickamer MA, Droger M, van der Heide A, Heyland DK, Houttekier D, Janssen DJA, Orsi L, Payne S, Seymour J, Jox RJ and Korfage IJ (2017) Definition and recommendations for advance care planning: an international consensus supported by the European Association for Palliative Care. The Lancet Oncology 18, e543-e551.

Robinson D and Wilson I (in press) Specialist housing for older people in an era of neoliberal transformation: exploring provision in England. Housing Studies, 1-19. Available online doi:10.1080/ 02673037.2021.1966394.

Rodrigues R (2020) Caring relationships and their role in users' choices: a study of users of Direct Payments in England. Ageing \& Society 40, 1469-1489.

Silverstein M (2016) Agency and normative self-governance. Australasian Journal of Philosophy 95, 517-528.

Simon HA (1955) A behavioral model of rational choice. Quarterly Journal of Economics 69, 99-118.

Simon HA (1956) Rational choice and the structure of the environment. Psychological Review 63, 129-138.

Smith A ([1776] 2000) An Inquiry into the Nature and Causes of the Wealth of Nations. New York, NY: Modern Library.

Stevens M, Manthorpe J, Glendinning C, Moran N, Jacobs S, Challis D, Wilberforce M, Fernandez JL, Knapp M, Jones K and Netten A (2011) Assessing the role of increasing choice in english social care services. Journal of Social Policy 40, 1-18.

Stiglitz JE (2008) Principal and agent (ii). In Macmillan P (ed). The New Palgrave Dictionary of Economics. London, UK: Palgrave Macmillan. https://doi.org/10.1057/978-1-349-95121-5_1274-2.

Stockwell S, Stubbs B, Jackson S, Fisher A, Yang L and Smith L (2021) Internet use, social isolation and loneliness in older adults. Ageing \& Society 41, 2723-2746.

Turnpenny A and Beadle-Brown J (2014) Use of quality information in decision-making about health and social care services - a systematic review. Health \& Social Care in the Community 23, 349-361.

Weathers E, O'Caoimh R, Cornally N, Fitzgerald C, Kearns T, Coffey A, Daly E, O'Sullivan R, McGlade C and Molloy DW (2016) Advance care planning: a systematic review of randomised controlled trials conducted with older adults. Maturitas 91, 101-109.

Woodhead C, Khondoker M, Lomas R and Raine R (2017) Impact of co-located welfare advice in healthcare settings: prospective quasi-experimental controlled study. British Journal of Psychiatry 211, 388-395.

Cite this article: Harding AJE (2022). Older people, information-giving and active agency practices in health, social care and housing: theory, evidence and reflections. Ageing \& Society 1-13. https://doi.org/ 10.1017/S0144686X21001884 